\title{
Modeling and Simulation of the Hydrogenation of $\alpha$-Methylstyrene on Catalytically Active Metal Foams as Tubular Reactor Packing
}

\author{
Farzad Lali, Felix-Aron Pahner, and Rüdiger Lange \\ Technische Universität Dresden, Münchener Strasse 41, 01062 Dresden, Germany \\ Correspondence should be addressed to Farzad Lali; farzad.lali@tu-dresden.de
}

Received 17 September 2015; Revised 1 December 2015; Accepted 9 December 2015

Academic Editor: Bhaskar Kulkarni

Copyright (C) 2016 Farzad Lali et al. This is an open access article distributed under the Creative Commons Attribution License, which permits unrestricted use, distribution, and reproduction in any medium, provided the original work is properly cited.

\begin{abstract}
This work presents a one-dimensional reactor model for a tubular reactor packed with a catalytically active foam packing with a pore density of 30 PPI in cocurrent upward flow in the example of hydrogenation reaction of $\alpha$-methylstyrene to cumene. This model includes material, enthalpy, and momentum balances as well as continuity equations. The model was solved within the parameter space applied for experimental studies under assumption of a bubbly flow. The method of orthogonal collocation on finite elements was applied. For isothermal and polytropic processes and steady state conditions, axial profiles for concentration, temperature, fluid velocities, pressure, and liquid holdup were computed and the conversions for various gas and liquid flow rates were validated with experimental results. The obtained results were also compared in terms of space time yield and catalytic activity with experimental results and stirred tank and also with random packed bed reactor. The comparison shows that the application of solid foams as reactor packing is advantageous compared to the monolithic honeycombs and random packed beds.
\end{abstract}

\section{Introduction}

The chemical industry aspires towards energy-efficient technologies for chemical reactors. Structured catalysts like open cell foam catalysts offer new possibilities for this purpose. The structure of interconnected struts in open celled foams enhances local turbulences caused by splitting and recombining the flow passing through foam packing. This turbulence improves mass and heat transfer. Another advantage is the high voidage in the metallic foam structure of up to $94 \mathrm{vol}$. $\%$ despite high specific geometrical surface area of up to ca. $2500 \mathrm{~m}^{2} \mathrm{~m}^{-3}$. This property allows the interphase and intraphase mass transfer limitation to be minimized with a very low pressure drop by controlling the washcoat layer thickness and structural parameters like strut thickness and cell size. Decreasing the particle size in a random packed bed of pellets for this purpose leads to unacceptably large pressure drops. Furthermore, the use of foam catalyst reduces the amount of the noble metal content needed for reaction compared to gauzes [1]. Also there is the possibility of lateral mixing of fluids in the foam structure between cells.
The properties mentioned make the foam catalysts beneficial for reactor packing for continuous tubular reactors.

The present study deals with the modeling and simulation of the hydrogenation of $\alpha$-methyl styrene (AMS) to cumene in a tubular reactor packed with foam catalysts. This hydrogenation reaction has been frequently used to characterize the reactor performance and overall mass transfer measurements [2-13]. Therefore, this reaction was used to characterize the performance of conventional catalyst supports or structured catalysts such as monoliths (also known as honeycombs) as well as random packed bed reactors.

The reactor modeled in this work was a tubular reactor with a diameter of $18 \mathrm{~mm}$ equipped with foam catalysts having a packed bed length of $50 \mathrm{~cm}$. The catalyst consisted of aluminum with a pore density of 30 PPI (Pores Per Inch). The catalytic washcoat consisted of a porous alumina support which contained $1.8 \mathrm{wt}$. \% Pd. The porous alumina layer had a specific surface area of ca. $120 \mathrm{~m}^{2} \mathrm{~g}^{-1}$ and a thickness of $17.8 \mu \mathrm{m}$. The multiphase flow of gas (hydrogen) and liquid (20 wt. \% of AMS in cumene) were introduced in cocurrent upward flow configuration into the reactor. It was reported 
<smiles>C=C(C)c1ccccc1</smiles>

FIGURE 1: Hydrogenation reaction of AMS.

by Wenmakers et al. [14]. who carried out a comparative modeling study for two types of carbon nanotubes with coated foam packing (washcoated solid foam and the Hairy foams) that for the upward flow configuration reactor height and the pressure drop were lower than for the other packing investigated. They also showed that much less noble metal was needed for foam packing operated in upward flow than for a packed bed of spherical particles.

One-dimensional momentum, heat, mass, and momentum balances were developed for steady state conditions for a multiphase flow introduced in upward flow direction. These balances took axial backmixing into account. The numerical solution was carried out by applying a combination of finite element analysis and orthogonal collocation methods for nonlinear systems of equations arising from a tubular reactor equipped with foam catalysts.

The results of the reactor simulation were validated with experimental data generated from a reactor that was geometrically similar to that mentioned above. Gas and fluid were introduced in upward flow. The experiments were carried out under isothermal conditions. The activity and the space time yields of a reactor equipped with the foam catalysts were also compared with the values in the literature.

\section{Modeling and Simulation}

Based on the one-dimensional model concept for each of the fluid phases, the curves for concentration, temperature, fluid velocity, pressure, and phase holdup were calculated by applying the collocation method. The reactor performances based on the calculated model were validated with the experimental data.

2.1. Model Reaction. The hydrogenation reaction of $\alpha$-methyl styrene to cumene was adopted. Figure 1 shows the model reaction.

This reaction is the model reaction which is often used as a model reaction. Its reaction kinetics has been investigated in several references $[12,15,16]$, and the material data is well known. For the simulation, the kinetic model of Jakobitz [15] was used:

$$
r_{\mathrm{int}}=\frac{k \cdot K_{\mathrm{H}_{2}} \cdot C_{\mathrm{H}_{2}}^{*} \cdot K_{\mathrm{AMS}} \cdot C_{\mathrm{AMS}}}{\left(1+K_{\mathrm{H}_{2}} \cdot C_{\mathrm{H}_{2}}^{*}\right) \cdot\left(1+K_{\mathrm{AMS}} \cdot C_{\mathrm{AMS}}\right)} .
$$

\section{Reactor Model}

The present reactor model consists of coupled balance equations for a tubular reactor packed with foam catalysts.

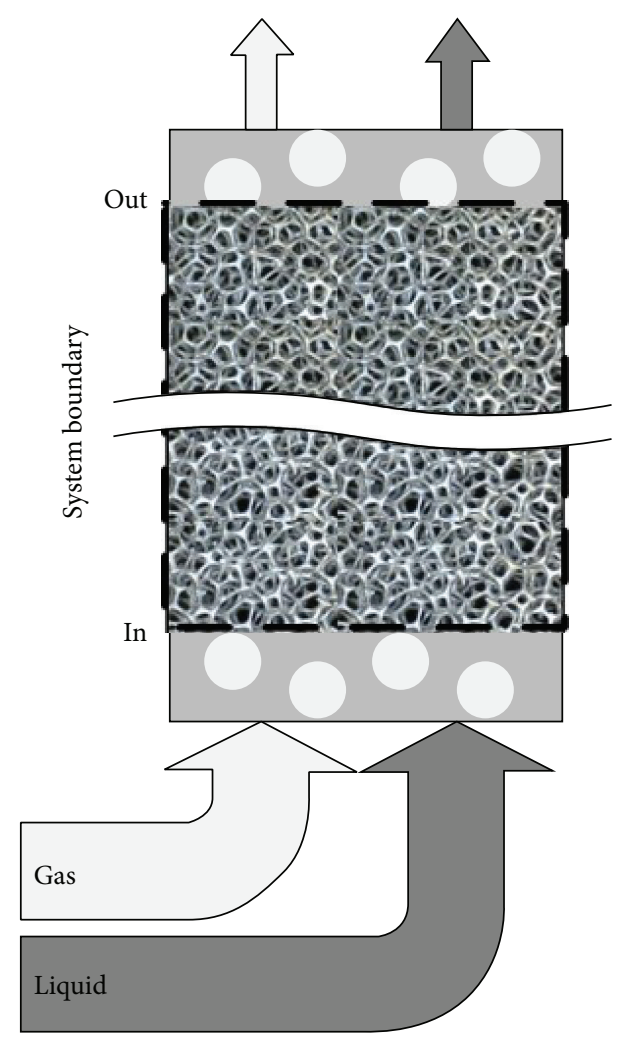

FIGURE 2: System boundary for the mathematical model [17].

Figure 2 shows the system boundaries. The system boundaries were set around the catalytic foam packing. The system is considered as closed-closed in terms of the boundary conditions. The conservation equations (balances) were written for a bubbly flow regime inside the foam packing for steady state conditions in an axial direction.

The mass balance equations with respect to particular species or phases are as follows.

For the liquid phase,

$$
\begin{aligned}
0= & -\frac{\partial}{\partial z}\left(C_{L, \mathrm{AMS}} \cdot u_{L}\right)+\frac{\partial}{\partial z}\left(D_{\mathrm{ax}, L} \cdot \frac{\partial C_{L, \mathrm{AMS}}}{\partial z}\right) \\
& +\left(-a_{\mathrm{LS}} \cdot k_{\mathrm{LS}} \cdot\left(C_{L, \mathrm{AMS}}-C_{S, \mathrm{AMS}}\right)\right) .
\end{aligned}
$$

For AMS and hydrogen,

$$
\begin{aligned}
0= & -\frac{\partial}{\partial z}\left(C_{L, \mathrm{H}_{2}} \cdot u_{L}\right)+\frac{\partial}{\partial z}\left(D_{\mathrm{ax}, L} \cdot \frac{\partial C_{L, \mathrm{H}_{2}}}{\partial z}\right)+\left(-a_{\mathrm{LS}}\right. \\
& \left.\cdot k_{\mathrm{LS}} \cdot\left(C_{L, \mathrm{H}_{2}}-C_{S, \mathrm{H}_{2}}\right)+a_{\mathrm{GL}} \cdot k_{\mathrm{GL}} \cdot\left(C_{\mathrm{H}_{2}}^{*}-C_{L, \mathrm{H}_{2}}\right)\right) .
\end{aligned}
$$

The equations above include the convective and dispersive effects and the exchange between phases. It is assumed that the gas phase consisted of pure hydrogen and therefore no exchange into the gas phase takes place.

For the solid phase (washcoat),

$$
\begin{aligned}
& 0=\left(a_{\mathrm{LS}} \cdot k_{\mathrm{LS}} \cdot\left(C_{L, \mathrm{AMS}}-C_{S, \mathrm{AMS}}\right)\right)+v_{\mathrm{AMS}} \cdot r_{\mathrm{eff}}, \\
& 0=\left(a_{\mathrm{LS}} \cdot k_{\mathrm{LS}} \cdot\left(C_{L, \mathrm{H}_{2}}-C_{S, \mathrm{H}_{2}}\right)\right)+\nu_{\mathrm{H}_{2}} \cdot r_{\mathrm{eff}} .
\end{aligned}
$$


The solid phase is characterized by an exchange with species entering from the liquid phase and the chemical reaction on the active catalytic center. The effective reaction rate is the intrinsic kinetics multiplied by the effectiveness factor:

$$
r_{\text {eff }}=r_{\text {int }} \cdot \eta \text {. }
$$

In order to simplify the solution in the first approximation, a plate geometry was chosen for the catalyst surface. The effectiveness factor was therefore calculated as

$$
\eta=\frac{\tanh \phi}{\phi} .
$$

The Thiele-modulus, $\phi$, showing the relationship between the kinetics and diffusion, is calculated as follows:

$$
\phi=d_{\mathrm{WC}} \cdot \sqrt{\frac{k}{D_{\mathrm{eff}}}} .
$$

Analogous to the mass balance equations, corresponding model equations for enthalpy conservation were written. An important assumption was that all phases have the same temperature. The corresponding terms for each phase are weighted by phase holdup. For the gas phase, it was assumed that convective heat transfer is predominant. The liquid phase was, however, characterized by convective heat transfer, and the term for heat diffusion/dispersion calculated from the $\Lambda_{r}(r)$ model [18] is applied only in an axial direction. Moreover, in the solid phase solely thermal conduction occurs. Furthermore, the heat of reaction and heat exchange with the ambient environment were considered:

$$
\begin{aligned}
0= & -\left[\varepsilon_{L} \cdot \frac{\partial}{\partial z}\left(T \cdot u_{L} \cdot c_{P, L} \cdot \rho_{L}\right)+\varepsilon_{G}\right. \\
& \left.\cdot \frac{\partial}{\partial z}\left(T \cdot u_{G} \cdot c_{P, G} \cdot \rho_{G}\right)\right]+\varepsilon_{L} \\
& \cdot\left[\frac{\partial}{\partial z}\left(\left(\frac{\Lambda_{\mathrm{ax}}}{\rho_{L} \cdot c_{P, L}}\right) \cdot \frac{\partial}{\partial z}\left(\rho_{L} \cdot c_{P, L} \cdot T\right)\right)\right] \\
& +\left[\left(\lambda_{\mathrm{Al}} \cdot\left(1-\varepsilon-\varepsilon_{\mathrm{WC}}\right)+\lambda_{\mathrm{AlO}} \cdot \varepsilon_{\mathrm{WC}}\right) \cdot \frac{\partial^{2} T}{\partial z^{2}}\right] \\
& +\left(-\Delta_{R} \mathrm{H} \cdot r_{\mathrm{eff}}\right)-\left(\frac{4}{d_{I}} \cdot k_{W} \cdot\left(T-T_{U}\right)\right) .
\end{aligned}
$$

In order to generate the profiles of velocities, pressure, and liquid holdup, it is necessary to consider relationships describing relevant hydrodynamics in addition to thermal and material balances. These equations are typically the momentum balances for each phase, and the continuity equation.

The phase momentum balances assume equilibrium. The momentum balances are as follows.
For the liquid phase,

$$
\begin{aligned}
0= & -\frac{\partial}{\partial z} \cdot\left(\rho_{L} \cdot u_{L}^{2} \cdot \varepsilon_{L} \cdot \frac{1}{\varepsilon}\right)-\frac{\partial}{\partial z} \cdot\left(\varepsilon_{L} \cdot p\right) \\
& -\left(\frac{1}{2} \cdot \frac{\varepsilon_{L}}{\varepsilon} \cdot a_{S} \cdot f_{\mathrm{WL}} \cdot \frac{\rho_{L}}{\varepsilon^{2}} \cdot u_{L}^{2}\right)-\frac{1}{2} \cdot\left(\frac{P_{\mathrm{GL}}}{A \cdot \varepsilon}\right) \cdot f_{\mathrm{GL}} \\
& \cdot \rho_{m} \cdot\left(u_{L}-u_{G}\right) \cdot\left|u_{L}-u_{G}\right|+g \cdot \varepsilon_{L} \cdot \rho_{L} .
\end{aligned}
$$

For the gas phase,

$$
\begin{aligned}
0= & -\frac{\partial}{\partial z} \cdot\left(\rho_{G} \cdot u_{G}^{2} \cdot \varepsilon_{G} \cdot \frac{1}{\varepsilon}\right)-\frac{\partial}{\partial z} \cdot\left(\varepsilon_{G} \cdot p\right) \\
& -\left(\frac{1}{2} \cdot \frac{\varepsilon_{G}}{\varepsilon} \cdot a_{S} \cdot f_{\mathrm{WG}} \cdot \frac{\rho_{G}}{\varepsilon^{2}} \cdot u_{G}^{2}\right)-\frac{1}{2} \cdot\left(\frac{P_{\mathrm{GL}}}{A \cdot \varepsilon}\right) \\
& \cdot f_{\mathrm{GL}} \cdot \rho_{m} \cdot\left(u_{G}-u_{L}\right) \cdot\left|u_{G}-u_{L}\right|+g \cdot \varepsilon_{G} \cdot \rho_{G} .
\end{aligned}
$$

The first terms on the right side of the equations stand for the convective momentum transport, and the next terms refer to the forces acting on the fluid. The gravitational forces are considered because of the vertical positioning of the reactor and the process being carried out in concurrent upward flow [19].

To complete the balance equations for the reactor, the continuity equations for gas and liquid phase are added:

$$
\begin{aligned}
& 0=\frac{\partial}{\partial z} \cdot\left(\frac{\varepsilon_{G}}{\varepsilon} \cdot \rho_{G} \cdot u_{G}\right), \\
& 0=\frac{\partial}{\partial z} \cdot\left(\frac{\varepsilon_{L}}{\varepsilon} \cdot \rho_{L} \cdot u_{L}\right) .
\end{aligned}
$$

To complete the aforementioned equation it is crucial to characterize the mass transfer coefficients as well as the mass transfer area.

For the mass transfer area between the liquid phase and the foam catalyst, the proportional geometrical surface area was considered; that is to say, complete wetting was not assumed:

$$
a_{\mathrm{LS}}=a_{S} \cdot \varepsilon_{L} .
$$

A correlation equation for the liquid solid phase mass transfer has been proposed by Cognet et al. [20]:

$$
\begin{aligned}
k_{\mathrm{LS}} & \\
= & \left(\operatorname{Re}_{L} \cdot \tau \cdot \mathrm{Sc}_{L}^{1 / 3}-16.9 \cdot \frac{d_{\mathrm{hyd}}}{d_{R}} \cdot\left(\mathrm{Re}_{L} \cdot \tau\right)^{\beta} \cdot \mathrm{Sc}_{L}^{1 / 3}\right) \\
& \cdot \frac{D_{\mathrm{ax}}}{d_{\mathrm{hyd}}} .
\end{aligned}
$$

The parameter $\beta$ stands for the pore density of the foam. For a 20 PPI foam $\beta=0.28$, and for a 45 PPI foam, $\beta=$ 0.25 . According to the literature data for the gas-liquid mass transfer the correlation proposed by Stemmet [21] was used. It was assumed that the gas liquid mass transfer for the reaction 
follows the correlation. For further precision, an enhancement factor should be considered:

$$
\begin{aligned}
k_{\mathrm{GL}} a_{\mathrm{GL}}= & \left(311 \cdot u_{\mathrm{G}, \mathrm{SV}}^{0.44} \cdot\left(\frac{u_{L, \mathrm{SV}} \cdot \rho_{L}}{\mu_{L}}\right)^{0.92} \cdot \mathrm{Sc}_{L}^{0.5}\right) \\
& \cdot \frac{D_{\mathrm{ax}}}{\varepsilon_{L}} .
\end{aligned}
$$

The gas liquid interface was calculated from the correlation proposed by Onda et al. [22, 23]. Stemmet et al. [24] has also used the same correlation:

$$
\begin{aligned}
& \frac{a_{\mathrm{GL}}}{a_{S}} \\
& =1 \\
& \quad-\exp \left(-1.45 \cdot\left(\frac{\sigma_{C}}{\sigma_{L}}\right)^{0.75} \cdot \mathrm{Re}_{L}^{0.1} \cdot \mathrm{Fr}^{-0.05} \cdot \mathrm{We}^{0.2}\right) .
\end{aligned}
$$

The correlation above was also used to determine the gas liquid circumference for the momentum balance:

$$
P_{\mathrm{GL}}=a_{\mathrm{GL}} \cdot A_{R}
$$

The coefficients of friction were calculated by applying the experimental data from our research group, measured by Schöneich [25]. The correlations described in (17) reflect the friction between phase interfaces:

$$
\begin{aligned}
f_{\mathrm{WL}}= & 23.5+\frac{133.5}{\mathrm{Re}_{L}}+\frac{580.9}{\mathrm{Re}_{L}^{2}}, \\
f_{\mathrm{WG}}= & 0.14+\frac{196.6}{\mathrm{Re}_{G}}+\frac{2760}{\mathrm{Re}_{G}^{2}}, \\
f_{\mathrm{GL}, 30 \mathrm{PPI}}= & -0.0005-0.092 \cdot\left(\frac{\mathrm{Re}_{L}}{\mathrm{Re}_{G}}\right)-0.9622 \\
& \cdot\left(\frac{\mathrm{Re}_{L}}{\operatorname{Re}_{G}}\right)^{2}+12.4220 \cdot\left(\frac{\mathrm{Re}_{L}}{\operatorname{Re}_{G}}\right)^{3} .
\end{aligned}
$$

To solve the differential equation system of the balance equations demands suitable boundary conditions as well as appropriate correlations. The following section describes the boundary conditions more closely.

\section{Boundary Conditions}

Because of their differential nature, the balance equations just described require appropriate boundary conditions to be solved numerically. The boundary conditions were set on the basis of Danckwerts' boundary conditions [26].

Assuming a closed-closed system, boundary conditions for the mass balances in the liquid phase result in (18) for the inlet:

$$
0=C_{L, i}^{\mathrm{ein}}-C_{L, i}^{0}-\left.\left(\frac{D_{\mathrm{ax}, L}}{u_{L} \cdot \varepsilon_{L}}\right)_{\text {ein }} \cdot \frac{\partial C_{L, i}}{\partial z}\right|_{\text {inlet }} .
$$

For the outlet, the equation for system boundaries is

$$
0=\left.\frac{\partial C_{L, i}}{\partial z}\right|_{\text {outlet }}
$$

where $i=\mathrm{AMS}, \mathrm{H}_{2}$.

For the mass balance in the solid phase no boundary conditions are needed because they are algebraic equations.

The boundary conditions for the heat balance are developed analogously to Danckwerts' BCs for the mass balance. For mass balance, molar flows at the system boundaries are balanced such that the heat flows entering the foam packing were taken for the boundary conditions of the heat balances:

$$
A^{-} u^{-} q^{-}=\left(-\left.a \cdot \frac{\partial q}{\partial z}\right|_{\text {inlet }} \cdot A^{+}\right)+A^{+} u^{+} q^{+}
$$

Equation (20) presents the general form of the boundary condition at the inlet. When appropriate heat flows are substituted in the left and the right sides of the equation, we obtain

$$
\begin{aligned}
& A \cdot\left(\varepsilon_{L}^{-} \cdot u_{L}^{-} \cdot q_{L}^{-}+\varepsilon_{G}^{-} \cdot u_{G}^{-} \cdot q_{G}^{-}\right)=-A \cdot\left(\frac{\Lambda_{\mathrm{ax}}}{\rho_{L} \cdot c_{P, L}}\right. \\
& \left.\left.\quad \cdot \frac{\partial q}{\partial z}\right|_{\text {inlet }} \cdot \varepsilon_{L}+\left.\frac{\lambda_{S}}{\rho_{S} \cdot c_{P, S}} \cdot \frac{\partial q}{\partial z}\right|_{\text {inlet }} \cdot \varepsilon_{S}\right)+A \cdot\left(\varepsilon_{L}^{+}\right. \\
& \left.\cdot u_{L}^{+} \cdot q_{L}^{+}+\varepsilon_{G}^{+} \cdot u_{G}^{+} \cdot q_{G}^{+}\right), \\
& \left(\varepsilon_{L}^{-} \cdot u_{L}^{-} \cdot q_{L}^{-}+\varepsilon_{G}^{-} \cdot u_{G}^{-} \cdot q_{G}^{-}\right)=-\left(\left.\frac{\Lambda_{\mathrm{ax}}}{\rho_{L} \cdot c_{P, L}} \cdot \frac{\partial q}{\partial z}\right|_{\text {inlet }}\right. \\
& \left.\left.\cdot \varepsilon_{L}^{+} \frac{\lambda_{S}}{\rho_{S} \cdot c_{P, S}} \cdot \frac{\partial q}{\partial z}\right|_{\text {inlet }} \cdot \varepsilon_{S}\right)+\left(\varepsilon_{L}^{+} \cdot u_{L}^{+} \cdot q_{L}^{+}+\varepsilon_{G}^{+}\right. \\
& \left.\quad \cdot u_{G}^{+} \cdot q_{G}^{+}\right), \\
& T^{0} \cdot\left(\varepsilon_{L}^{0} \cdot u_{L}^{0} \cdot \rho_{L}^{0} \cdot c_{P, L}^{0}+\varepsilon_{G}^{0} \cdot u_{G}^{0} \cdot \rho_{G}^{0} \cdot c_{P, G}^{0}\right) \\
& \quad=-\left(\left.\frac{\Lambda \Lambda_{\mathrm{ax}}}{\rho_{L} \cdot c_{P, L}} \cdot \frac{\partial\left(\rho_{L} \cdot c_{P, L} \cdot T\right)}{\partial z}\right|_{\text {inlet }} \cdot \varepsilon_{L}+\lambda_{S}\right. \\
& \left.\left.\quad \frac{\partial T}{\partial z}\right|_{\text {inlet }} \cdot \varepsilon_{S}\right)_{\text {inlet }}+T_{\text {inlet }} \cdot\left(\varepsilon_{L} \cdot u_{L} \cdot \rho_{L} \cdot c_{P, L}+\varepsilon_{G}\right.
\end{aligned}
$$

Rearranging (23) and substituting the independent variables result in (24) for the boundary condition at the inlet of the foam packing:

$$
\begin{aligned}
0= & T_{\text {ein }} \cdot\left(\varepsilon_{L} \cdot u_{L} \cdot \rho_{L} \cdot c_{P, L}+\varepsilon_{G} \cdot u_{G} \cdot \rho_{G} \cdot c_{P, G}\right)_{\text {inlet }} \\
& -T^{0} \cdot\left(\varepsilon_{L}^{0} \cdot u_{L}^{0} \cdot \rho_{L}^{0} \cdot c_{P, L}^{0}+\varepsilon_{G}^{0} \cdot u_{G}^{0} \cdot \rho_{G}^{0} \cdot c_{P, G}^{0}\right) \\
& -\left(\left.\frac{\Lambda_{\mathrm{ax}}}{\rho_{L} \cdot c_{P, L}} \cdot \frac{\partial\left(\rho_{L} \cdot c_{P, L} \cdot T\right)}{\partial z}\right|_{\text {inlet }} \cdot \varepsilon_{L}\right. \\
& \left.+\left.\left(\lambda_{\mathrm{Al}} \cdot\left(1-\varepsilon-\varepsilon_{C}\right)+\lambda_{\mathrm{AlO}} \cdot \varepsilon_{C}\right) \cdot \frac{\partial T}{\partial z}\right|_{\text {inlet }}\right)_{\text {inlet }} .
\end{aligned}
$$


Equation (25) describes conditions at the outlet of the foam packing. Because it describes conditions at the reactor exit and because no chemical reaction can occur, the temperature gradients are zero:

$$
0=\left.\frac{\partial T}{\partial z}\right|_{\text {outlet }} .
$$

The boundary conditions for the momentum balance were developed using the inlet pressure on the system boundaries. Both static and dynamic pressures were considered:

$$
\begin{aligned}
0= & \frac{1}{2} \cdot\left[\left(\frac{\rho_{L} \cdot u_{L}^{2} \cdot \varepsilon_{L}}{\varepsilon}\right)-\left(\frac{\rho_{L}^{0} \cdot\left(u_{L}^{0}\right)^{2} \cdot \varepsilon_{L}^{0}}{\varepsilon^{0}}\right)\right] \\
& +\left(\frac{\varepsilon_{L}}{\varepsilon} \cdot p\right)-\left(\frac{\varepsilon_{L}^{0}}{\varepsilon^{0}} \cdot p^{0}\right) .
\end{aligned}
$$

It should be mentioned that $\varepsilon^{0}=1$ and $\varepsilon_{L}^{0}$ was calculated from the superficial velocities. Analogously to the boundary conditions of the gas phase, we obtain

$$
\begin{aligned}
0= & \frac{1}{2} \cdot\left[\left(\frac{\rho_{G} \cdot u_{G}^{2} \cdot \varepsilon_{G}}{\varepsilon}\right)-\left(\frac{\rho_{G}^{0} \cdot\left(u_{G}^{0}\right)^{2} \cdot \varepsilon_{G}^{0}}{\varepsilon^{0}}\right)\right] \\
& +\left(\frac{\varepsilon_{G}}{\varepsilon} \cdot p\right)-\left(\frac{\varepsilon_{G}^{0}}{\varepsilon^{0}} \cdot p^{0}\right) .
\end{aligned}
$$

The boundary conditions ((26) and (27)) were used in modified form in (28) for the inlet pressure and in (29) for liquid holdup:

$$
\begin{aligned}
p^{\text {ein }} & \cdot\left(\frac{\varepsilon_{G}^{\text {inlet }}}{\varepsilon}\right) \\
= & \varepsilon_{G}^{0} \cdot\left(\frac{1}{2} \cdot \rho_{G}^{0} \cdot \frac{\left(u_{G}^{0}\right)^{2}}{\varepsilon^{0}}+\frac{p^{0}}{\varepsilon^{0}}\right)-\varepsilon_{G}^{\text {ein }} \\
& \cdot\left(\frac{1}{2} \cdot \rho_{G}^{\text {ein }} \cdot \frac{\left(u_{G}^{\text {inlet }}\right)^{2}}{\varepsilon}\right), \\
\varepsilon_{L}^{\text {ein }} & \cdot\left(\frac{1}{2} \cdot \rho_{L}^{\text {inlet }} \cdot \frac{\left(u_{L}^{\text {inlet }}\right)^{2}}{\varepsilon}+\frac{p^{\text {inlet }}}{\varepsilon}\right) \\
= & \varepsilon_{L}^{0} \cdot\left(\frac{1}{2} \cdot \rho_{L}^{0} \cdot \frac{\left(u_{L}^{0}\right)^{2}}{\varepsilon^{0}}+\frac{p^{0}}{\varepsilon^{0}}\right) .
\end{aligned}
$$

Finally, the boundary conditions for the continuity equation, in which the mass flow per cross-sectional area is applied, are described in

$$
\begin{aligned}
& 0=\rho_{G}^{\text {ein }} \cdot u_{G}^{\text {ein }} \cdot \frac{\varepsilon_{G}^{\text {ein }}}{\varepsilon}-\rho_{G}^{0} \cdot u_{G}^{0} \cdot \frac{\varepsilon_{G}^{0}}{\varepsilon_{0}}, \\
& 0=\rho_{L}^{\text {ein }} \cdot u_{L}^{\text {ein }} \cdot \frac{\varepsilon_{L}^{\text {ein }}}{\varepsilon}-\rho_{L}^{0} \cdot u_{L}^{0} \cdot \frac{\varepsilon_{L}^{0}}{\varepsilon_{0}} .
\end{aligned}
$$

The gradients of temperature, liquid velocities, pressure, and holdup in an axial direction were investigated by a numerical solution of the aforementioned reactor model with appropriate boundary conditions. The next section discusses the numerical solution method adopted.

\section{Numerical Solution}

A method of polynomial approximation was adopted as a numerical solution method for the reactor model presented in Section 3. Specifically, the orthogonal collocation method on finite elements (OCFE) was applied [27]. This method is based on the orthogonal collocation method [28-31]. This method has advantages in case of strongly nonlinear model systems in reaction engineering. The nonlinearities are typically caused by Arrhenius equations describing the reaction rate. Therefore, this method is recommended frequently in the literature for calculation of differential equations in reaction engineering [28]. The OCFE method uses defined supporting points of the model equations instead of the approximation polynomials. Those supporting points are the zero points of the orthogonal polynomials, for which the collocation matrices with derivative factors are calculated. For these supporting points, the derivative factors of the 1st and 2 nd order were calculated. In the case of the OCFE, these derivative factors must be scaled or cascaded in order to adapt them to the problem.

The finite elements should serve to simplify the solution of orthogonal collocation. For high resolution, many supporting points are needed. Applying orthogonal collocation results in many polynomials of higher orders. But polynomials of higher order tend to oscillate, and this behavior made them hard to fit to a curve. Splitting the data into a number of smaller, overlapping groups in finite elements results in smaller polynomials for each group. Applied to all groups, this process can be used to estimate the gradients for each group that can be applied several times consecutively to represent the gradients of model parameters.

The link points of the polynomials as well as two marginal points are connected by a spline interpolation. The spline interpolation is solved using a tridiagonal matrix by applying the Thomas algorithm [32]. Before the modeled balance equations can be solved, they must first be transformed such that the derivatives are replaced by the product of the collocation matrix and the appropriate derivative factor, and the vector of parameters in every supporting point. Also, the left side of the equation has to be rearranged such that it becomes zero when it is solved. The resulting equation is an algebraic equation which can be solved by varying the parameters until the left side of the equation approaches zero.

\section{Program Development}

The solution of the balance equations was implemented in MATLAB. To develop the program, the independent parameters were declared and then a subprogram was written for collocation matrices. In the main script the initial conditions for the solver were determined, and the position vectors were 
TABLE 1: Simulation parameters.

\begin{tabular}{lccc}
\hline Parameter & Symbol & Value & Unit \\
\hline Volumetric flow rate liquid & $\dot{V}_{L}$ & $10 \cdots 40$ & $\mathrm{~mL} \mathrm{~min}^{-1}$ \\
Volumetric flow rate gas & $\dot{V}_{G}$ & $50 \cdots 200$ & $\mathrm{~mL} \mathrm{~min}^{-1}$ \\
Mass fraction of AMS & $w_{\text {AMs }}$ & 20 & wt. \% \\
Inlet pressures & $p_{\text {tot }}$ & 1,10 & Bar \\
Initial temperatures & $T_{\text {in }}$ & 393,313 & $\mathrm{~K}$ \\
Reactor length & $l_{R}$ & 0.5 & $\mathrm{~m}$ \\
Reactor diameter & $d_{R}$ & 0.017 & $\mathrm{~m}$ \\
Pore density of foams & $\beta$ & 30 & $\mathrm{PPI}$ \\
Number of collocation points & $n_{P}$ & 50 & - \\
Number of finite elements & $n_{E}$ & 1 & - \\
\hline
\end{tabular}

calculated. After that the solver together with the balance equations was called as a subprogram. The solver applies the trust region-dogleg algorithm, which is suitable for solution of stiff equation systems. The balances described are calculated so that the left sides of the equations approach zero while the values of the marginal and link points are calculated by applying the boundary conditions and spline interpolation in the subprogram. At every iteration step the variables and kinetics were redefined. When the solver reaches an abort criterion, the internal solution points were output. Finally, the simulation data over the reactor length was output in graphical form.

Because of the high stiffness of the problem, a stepwise solution was necessary beginning with small variations of the input parameters producing preliminary solutions. The final solution was obtained by additional iterations that took the preliminary solutions as new start values.

\section{Results and Discussion}

A tubular reactor with an inner diameter of $17 \mathrm{~mm}$ was packed with a foam catalyst with a pore density of 30 PPI. The fluids (AMS, cumene, and hydrogen) were introduced in cocurrent upward flow. The process was carried out isothermally. The parameter window of the simulation is shown in Table 1. The flow regime in this parameter window varies from bubbly at lower flow rates to slug flow. This fact was confirmed by hydrodynamic experiments.

The simulation results for a liquid flow rate of $20 \mathrm{~mL} \mathrm{~min}^{-1}$ are shown in Figures $3-10$. For this liquid flow rate, gas flow rates of $90,110,160,180$, and $230 \mathrm{~mL} \mathrm{~min}^{-1}$ were simulated. Figure 3 shows the concentration gradients of AMS in the liquid phase. As gas flow rate increases, the concentration gradients at the beginning of the reactor change smoothly but, near the end of the reactor, these changes become more abrupt. As shown in Figure 4, the highest conversion was attained at the end of the reactor at the highest gas flow rate.

The concentration gradients of hydrogen in the liquid phase over the catalytically active foam packing are depicted in Figure 8. It can be seen here that the concentrations of hydrogen at the reactor inlet do not equal zero due to axial backmixing in the reactor and because the simulation did

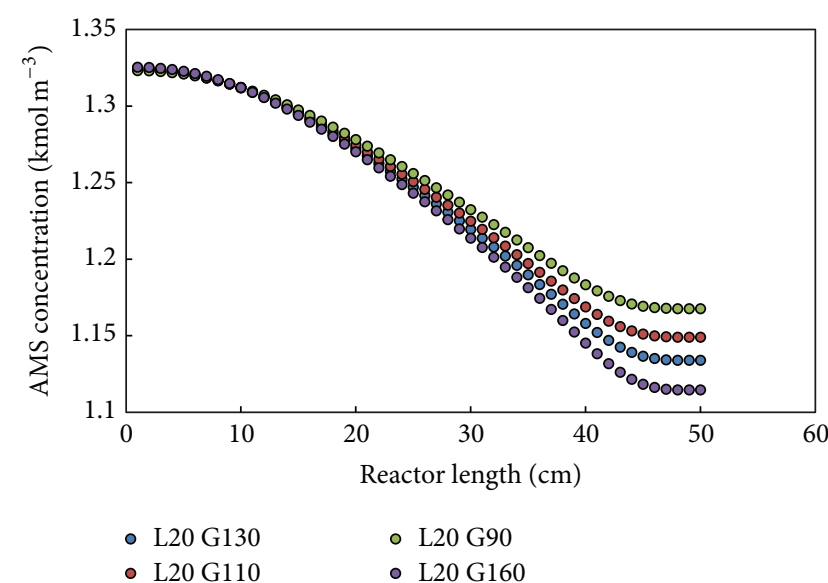

FIGURE 3: Calculated concentrations of AMS along reactor length for a liquid flow rate of $20 \mathrm{~mL} \mathrm{~min}^{-1}$ and various gas flow rates.

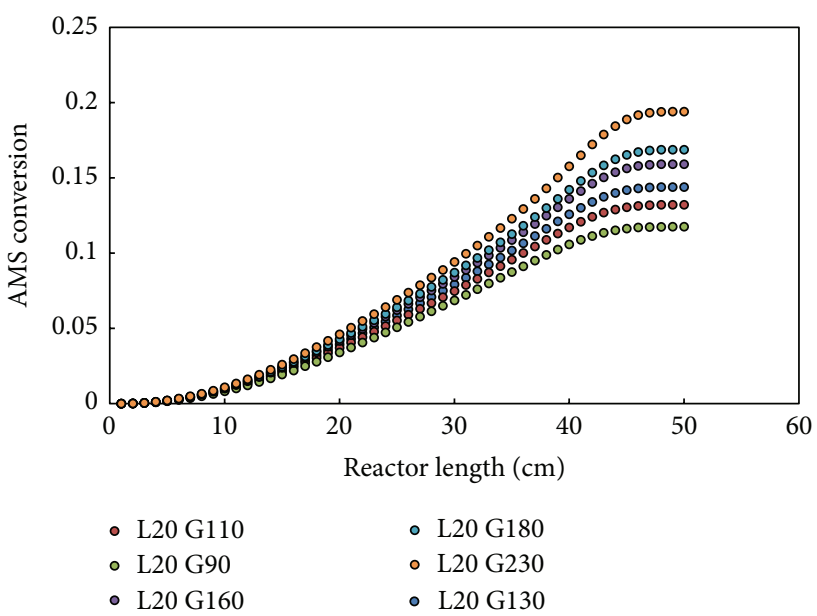

FIGURE 4: Calculated AMS conversion along the reactor length for a liquid flow rate of $20 \mathrm{~mL} \mathrm{~min}{ }^{-1}$ and various gas flow rates.

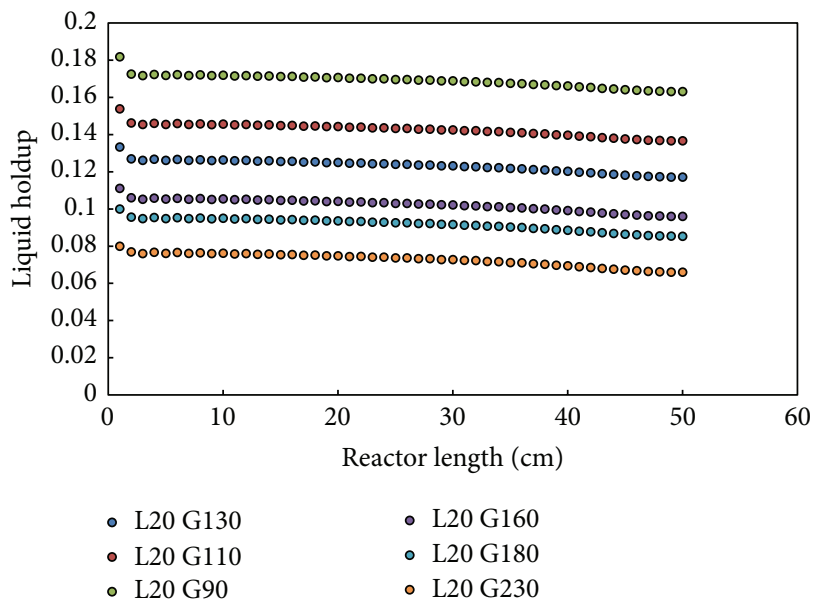

FIGURE 5: Calculated liquid holdups along the reactors for a liquid flow rates of $20 \mathrm{~mL} \mathrm{~min}^{-1}$ and various gas flow rates. 


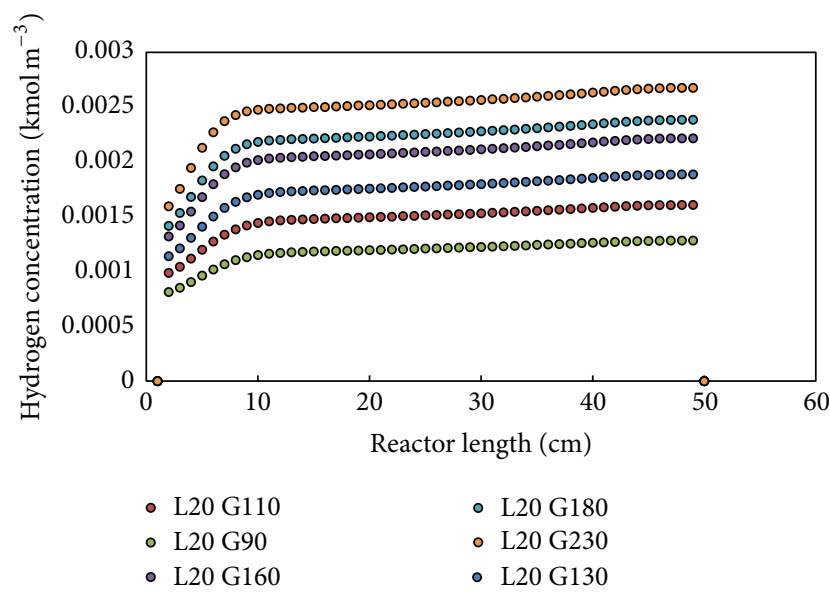

FIGURE 6: Calculated hydrogen concentration in the washcoat layer along the reactor length for a liquid flow rate of $20 \mathrm{~mL} \mathrm{~min}^{-1}$ and various gas flow rates.

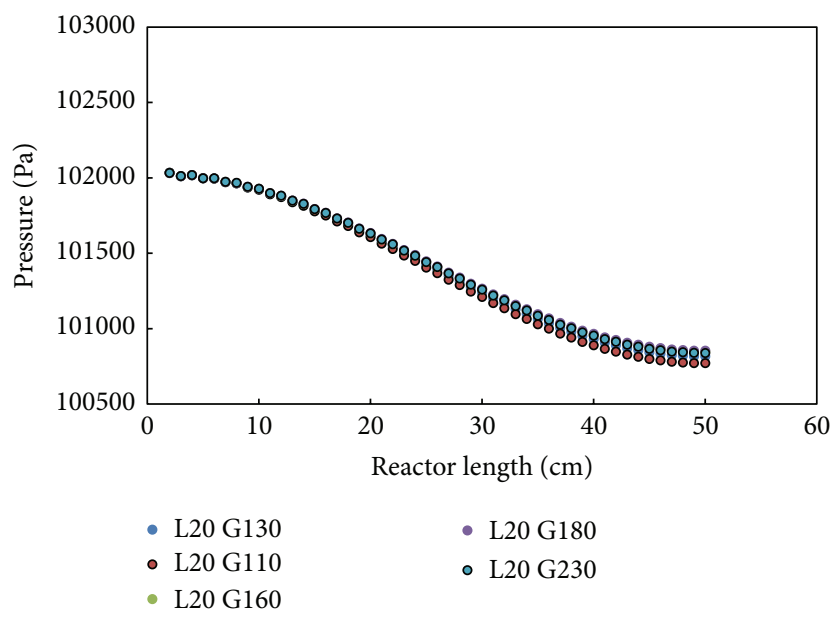

FIGURE 7: Calculated pressure profiles in the reactor for a liquid flow rate of $20 \mathrm{~mL} \mathrm{~min}^{-1}$ and various gas flow rates.

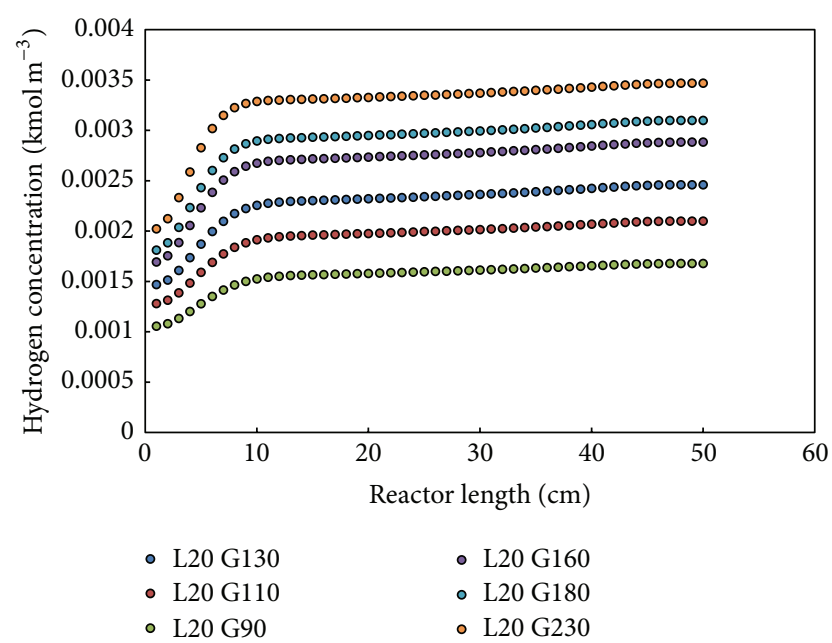

FIGURE 8: Calculated concentrations of hydrogen in the liquid phase along the reactor for a liquid flow rate of $20 \mathrm{~mL} \mathrm{~min}^{-1}$ and various gas flow rates.

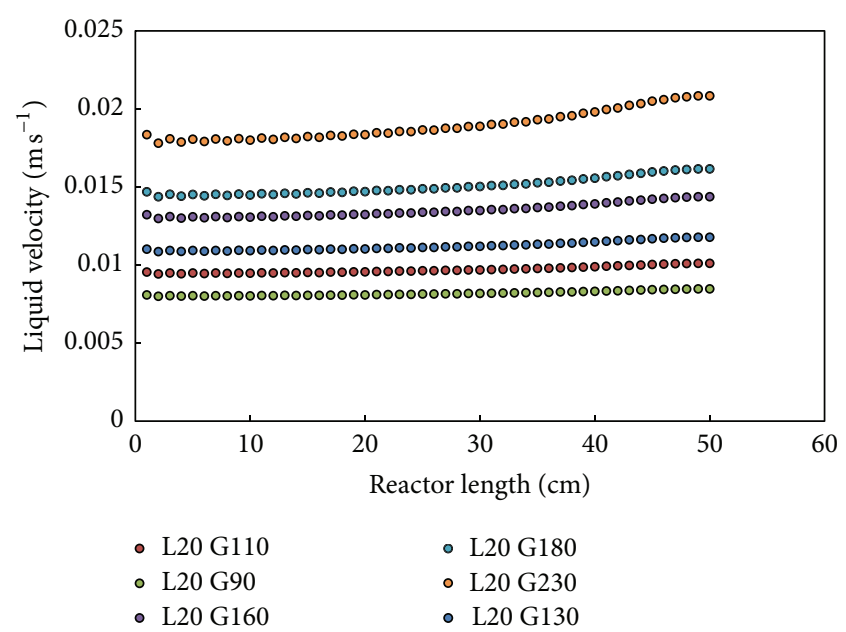

FIGURE 9: Calculated liquid velocity profiles along the reactor for a

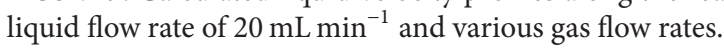

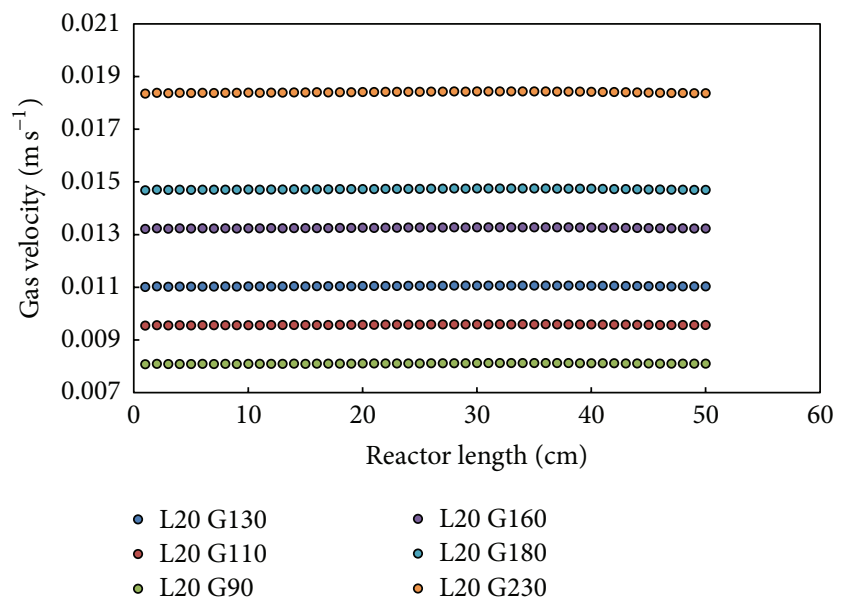

FIGURE 10: Calculated gas velocity profiles along the reactor for a liquid flow rate of $20 \mathrm{~mL} \mathrm{~min}^{-1}$ and various gas flow rates.

not assume a presaturated liquid. In the first 10 centimeters of the foam packing, a maximum of hydrogen concentration was reached which was not necessarily as high as the saturation concentration. The hydrogen concentration after $10 \mathrm{~cm}$ remained almost constant until the end of the foam packing. A saturation concentration can be only reached after the AMS has been completely converted. The maximum shows a kind of equilibrium between the gas supply from the reactor inlet and gas consumption by the reaction. It is influenced by increasing the reaction rate and solubility at higher temperatures. The concentration of hydrogen in the washcoat showed similar profiles, as is seen in Figure 6.

The profiles of fluid velocities in the reactor are depicted in Figures 9 and 10 for liquid and gas, respectively. The liquid flow rates show a slight increase, which is induced by the gas flow rate, whereas the gas velocities do not change appreciably. The profiles of pressure are depicted in Figure 7, which show that the pressure in the reactor decreases slightly. 
The simulated liquid hold-up changes slightly along the reactor (Figure 5).

\section{Validation with Experimental Results}

The simulation results enable us to compare reactor performance with other reactor concepts. This comparison was done for the same reaction (hydrogenation of AMS to cumene) under similar process conditions, with a stirred tank reactor with a fine slurry catalyst [16] and a tubular reactor with catalytic active foams [33]. The results of the comparison are depicted in Figure 11. This figure compares the catalytic activities (molar flow of product per Pd mass) and the space time yield for the three reactor types. Among the reactor types, the highest activity and space time yield was found to be the stirred tank with fine slurry catalyst [16], with a moderate usage of catalyst due to very small particle size. The reaction rate was almost as high as the intrinsic reaction rate. In terms of catalytic activity, the tubular reactors with a catalytic active foam packing [33] and the present simulation results are ranked after the stirred tank. Tubular reactors with catalytic foam packing show a very efficient usage of catalyst and good space time yield. Lower activities and average space time yield were found for a trickle bed reactor [34], while the catalyst usage was typical and the hydrogen consumption was about $33 \%$ higher than foam catalysts. The comparison with the trickle bed reactor makes it clear that by using the foam catalysts, the activity and space time yield was improved as high as a factor 10. Moreover, the catalyst was used more efficiently by the foam catalysts because $90 \%$ less Pd was used compared to the trickle bed reactor. Therefore, in terms of economy, the tubular reactors with catalytically active foams are highly recommended, especially for multiphase reactions with heterogeneous catalysts.

The model described here was validated by the experimental results presented in the previous chapter, which were the same as the conditions presented in Table 1 . Figure 12 shows the parity diagram for liquid flow rates of 20,30, and $40 \mathrm{~mL} \mathrm{~min}{ }^{-1}$ and various gas flow rates. Agreement with about $80 \%$ of the experimental results was obtained.

\section{Summary and Conclusions}

The present work compared the efficiency of foam catalysts to improve reactor performance compared with conventional reactors. A reactor model including appropriate correlations for a tubular reactor with catalytically active foam catalysts was developed, and MATLAB simulations were performed to compare foam catalyst reactors with conventional reactors such as trickle bed and monolithic honeycombs for multiphase reactions. Simulation results were generated for a tubular reactor with a diameter of $17 \mathrm{~mm}$ and a foam packing length of $50 \mathrm{~cm}$, a foam pore density of $30 \mathrm{PPI}, \gamma$-alumina washcoat with a Pd loading of $1.7 \mathrm{wt} . \%$ at $120^{\circ} \mathrm{C}$, and $1 \mathrm{bar}$ of inlet pressure. The reactor model included the material, energy, and momentum balances, as well as the continuity equation. The appropriate boundary conditions for the inlet and outlet were presented and discussed according to

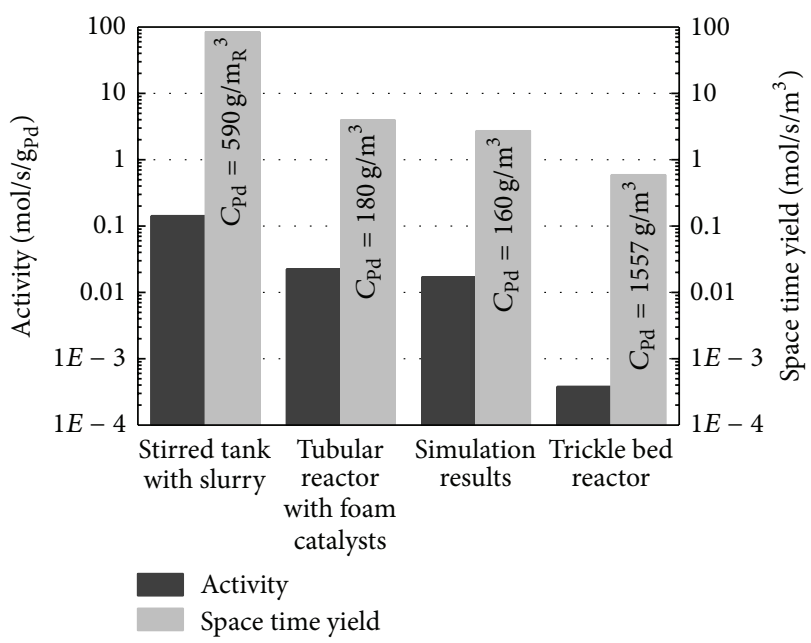

FIGURE 11: Comparison of the reactor performance of continuous tubular reactor with foam catalysts with conventional reactors; stirred tank with a fine slurry catalyst $\left(T=45.5^{\circ} \mathrm{C}, P=1.51\right.$ bar $)$ Meille et al. [16]; tubular reactor with catalytically active foam packing in cocurrent upward flow $\left(40^{\circ} \mathrm{C}, 10 \mathrm{bar}, V_{L}=20 \mathrm{~mL} \mathrm{~min}^{-1}\right)$ Lali [33]; the simulation results of the present work $\left(40^{\circ} \mathrm{C}, 10 \mathrm{bar}\right.$, $\left.V_{L}=20 \mathrm{~mL} \mathrm{~min}^{-1}\right)$ Lali [33]; trickle bed reactor $\left(40^{\circ} \mathrm{C}, 10 \mathrm{bar}, V_{L}=\right.$ $25 \mathrm{~mL} \mathrm{~min}^{-1}$ ) Schubert [34].

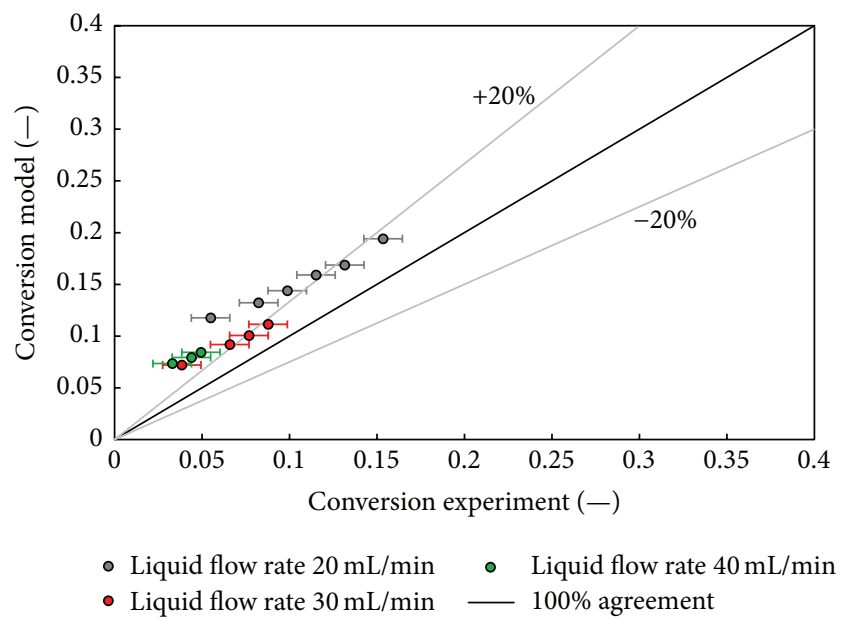

Figure 12: Parity chart of the model and experimental results.

Danckwerts' approach for closed-closed systems. The method of orthogonal collocation on finite elements was applied to develop an algebraic system of equations which was solved by means of the trust region dogleg method implemented in MATLAB. The data from the simulations as well as the experimental results prove that foam catalysts can achieve higher activities compared to monolithic honeycombs or random packed beds. An index of the performance of the foam catalyst reactor is the one provided by the following summary. With an $85 \%$ savings of catalyst mass, the foam catalysts were 3 times more active than the monolithic honeycomb. Compared to a trickle bed reactor with a random packed bed of catalyst pellets at normal or periodical process mode, the activity of the foam catalysts is around 40 times 
higher. Based on these insights, catalytically active foam packing is promising prospects for process intensification in multiphase reactors.

\section{Abbreviations}

AMS: $\alpha$-Methylstyrene

PPI: Pores Per Inch.

\section{Nomenclature}

A: Cross-sectional area $\left[\mathrm{m}^{2}\right]$

Bo: Bodenstein number $\left[u_{z} l_{R} D_{z}^{-1}\right]$

$C_{j}$ : Molar concentration of species $j\left[\mathrm{kmol} \mathrm{m}^{-3}\right]$

$C_{j}^{0}$ : $\quad$ Molar concentration of species $j$ before inlet $\left[\mathrm{kmol} \mathrm{m}^{-3}\right]$

$C_{j}^{\text {in }}$ : Molar concentration of species $j$ at inlet $\left[\mathrm{kmol} \mathrm{m}^{-3}\right]$

$C_{j}^{\text {out }}$ : Molar concentration of species $j$ at outlet $\left[\mathrm{kmol} \mathrm{m}^{-3}\right]$

$C_{j}^{*}$ : Equilibrium concentration of species $j$ $\left[\mathrm{kmol} \mathrm{m}^{-3}\right]$

$C_{\mathrm{Pd}}$ : Pd concentration per reactor volume $\left[\mathrm{g} \mathrm{m}_{\mathrm{R}}^{-3}\right]$

$D_{\mathrm{ax}}:$ Axial dispersion coefficient $\left[\mathrm{m}^{2} \mathrm{~s}^{-1}\right]$

$D_{z}:$ Axial dispersion in $z$ direction $\left[\mathrm{m}^{2} \mathrm{~s}^{-1}\right]$

$D_{\text {eff }}:$ Effective diffusivity $\left[\mathrm{m}^{2} \mathrm{~s}^{-1}\right]$

$D: \quad$ Diffusivity $\left[\mathrm{m}^{2} \mathrm{~s}^{-1}\right]$

$E_{A, i}:$ Activation energy $\left[\mathrm{kJ} \mathrm{mol}^{-1}\right]$

$E(t)$ : Probability density function of residence times

$\mathrm{Fr}_{j}$ : Froude number of the phase $j\left[u_{j, \mathrm{SV}}^{2} a_{S} \mathrm{~g}^{-1}\right]$

$K_{j}$ : Adsorption equilibrium constant of species $j$ $\left[\mathrm{m}^{3} \mathrm{kmol}^{-1}\right]$

Ne: Newton number $\left[\mathrm{P} \rho^{-1} n^{-3} d^{-5}\right]$

$P_{i j}$ : Circumference of the boundary surface $i j[\mathrm{~m}]$

$R: \quad$ Universal gas constant $\left[\mathrm{J} \mathrm{mol}^{-1} \mathrm{~K}^{-1}\right]$

$\operatorname{Re}_{j}$ : Reynolds number of the phase $j\left[u_{j, \mathrm{SV}} d_{\text {hyd }} \rho_{j} \mu_{j}^{-1} \varepsilon^{-1}\right]$

$\mathrm{Sc}_{j}$ : Schmidt number of phase $j\left[\mu_{j} D^{-1} \rho_{j}^{-1}\right]$

$T: \quad$ Absolute temperature $[\mathrm{K}]$

$V_{R}:$ Reactor volume $\left[\mathrm{m}^{3}\right]$

$V_{w}:$ Washcoat volume $\left[\mathrm{m}^{3}\right]$

$\dot{V}_{\text {in }}:$ Volumetric flow rate $\left[\mathrm{m}^{3} \mathrm{~s}^{-1}\right]$

$\mathrm{We}_{j}$ : Weber number of the phase $j\left[u_{j, S \mathrm{~V}}^{2} \rho_{j} \sigma_{j}^{-1} a_{S}^{-1}\right]$

$a$ : Volume-specific interphase surface area $\left[\mathrm{m}^{2} \mathrm{~m}^{-3}\right]$

$a_{S}$ : Volume-specific geometrical surface area of a foam substrate $\left[\mathrm{m}^{2} \mathrm{~m}^{-3}\right]$

$C_{\mathrm{H}}^{*}$ : Saturation concentration of hydrogen $\left[\mathrm{kmol} \mathrm{m}^{-3}\right]$

$d: \quad$ Diameter of stirrer $[\mathrm{m}]$

$d_{\text {hyd }}:$ Hydraulic diameter $\left[4 \varepsilon a_{S}^{-1}\right]$

$d_{\mathrm{WC}}$ : Washcoat layer thickness [m]

$d_{R}: \quad$ Reactor diameter $[\mathrm{m}]$

$k$ : Reaction rate constant for AMS hydrogenation $\left[\mathrm{s}^{-1}\right]$

$k_{i j}$ : Mass transfer coefficient between the phases $i$ and $j\left[\mathrm{~m} \mathrm{~s}^{-1}\right]$

$p$ : $\quad$ Pressure $[\mathrm{Pa}]$ q: $\quad$ Specific heat $\left[\mathrm{J} \mathrm{m}^{-3}\right]$

$q$ : Volume throughput $\left[\mathrm{m}^{3} \mathrm{~s}^{-1}\right]$

$r_{\text {eff }}:$ Effective reaction rate $\left[\mathrm{mol} \mathrm{g}^{-1} \mathrm{~s}^{-1}\right]$

$r_{\text {int }}$ : Intrinsic reaction rate per gram of catalyst $(\mathrm{Pd})$ $\left[\mathrm{mol} \mathrm{g}_{\mathrm{Pd}}^{-1} \mathrm{~s}^{-1}\right.$ ]

$u_{j}$ : Velocity of the phase $j\left[\mathrm{~m} \mathrm{~s}^{-1}\right]$.

\section{Greek Symbols}

$\Delta_{R} \mathrm{H}$ : Reaction enthalpy [ $\left.\mathrm{kmol}^{-1}\right]$

$\Lambda_{\mathrm{ax}}$ : Axialer Dispersionskoeffizient der Temperatur $\left[\mathrm{W} \mathrm{m}^{-1} \mathrm{~K}^{-1}\right.$ ]

$\beta: \quad$ Factor for PPI number of the foam [-]

$\varepsilon: \quad$ Void ratio [-]

$\varepsilon_{j}: \quad$ Holdup of the species $j[-]$

$\lambda: \quad$ Thermal conductivity $\left[\mathrm{W} \mathrm{m}^{-1} \mathrm{~K}^{-1}\right]$

$\eta: \quad$ Effectiveness factor $[-]$

$\mu_{j}: \quad$ Dynamic viscosity of the species $j[\mathrm{Pas}]$

$v_{j}$ : Stoichiometric coefficient of the species $j[-]$

$v$ : $\quad$ Kinematic viscosity $\left[\mathrm{m}^{2} \mathrm{~s}^{-1}\right]$

$\sigma: \quad$ Surface tension $\left[\mathrm{kg} \mathrm{s}^{-2}\right]$

$\rho_{j}$ : Density of the species $j\left[\mathrm{~kg} \mathrm{~m}^{-3}\right]$

$\tau: \quad$ Tortuosity [-]

$\varphi$ : Thiele modulus [-].

Indices

-: $\quad$ Bottom of the system boundary

+: $\quad$ Top of the system boundary

0 : Initial condition

C: Critical condition

G: Gas phase

I: $\quad$ Inside

L: $\quad$ Liquid phase

$R: \quad$ Reactor

S: $\quad$ Solid phase

$U$ : Ambient

$W:$ Wall

Al: Aluminum

GL: Gas-liquid phase boundary

LS: Liquid-solid phase boundary

SV: Superficial velocity

WC: Washcoat

AlO: Alumina

out: Outlet cross section

in: Inlet cross section.

\section{Conflict of Interests}

The authors declare that there is no conflict of interests regarding the publication of this paper.

\section{Acknowledgments}

The authors acknowledge support by the German Research Foundation and the Open Access Publication Funds of the TU Dresden. 


\section{References}

[1] L. E. Campbell, "Catalyst for production of nitric acid by oxidation of ammonia," US 5336656 A, 1993.

[2] S. Haase, "Chair of chemical process engineering and plant design," in Minichannel Flow Reactors for Gas Liquid Solid Reactions, Technische Universität Dresden, Dresden, Germany, 2012.

[3] S. Haase, T. Bauer, R. Langsch, and R. Lange, "Modelling of gas/liquid/solid reactions in strict separation for the regime of the forcer flux," Chemie Ingenieur Technik, vol. 81, no. 12, pp. 1991-1998, 1991.

[4] S. Haase, R. Langsch, T. Bauer, and R. Lange, "Impact of spherical catalyst particles on gas-liquid flow regimes in minichannels with square cross section," Chemie-Ingenieur-Technik, vol. 86, no. 4, pp. 467-475, 2014.

[5] S. Haase, M. Weiss, R. Langsch, T. Bauer, and R. Lange, "Hydrodynamics and mass transfer in three-phase composite minichannel fixed-bed reactors," Chemical Engineering Science, vol. 94, pp. 224-236, 2013.

[6] M. T. Kreutzer, P. Du, J. J. Heiszwolf, F. Kapteijn, and J. A. Moulijn, "Mass transfer characteristics of three-phase monolith reactors," Chemical Engineering Science, vol. 56, no. 21-22, pp. 6015-6023, 2001.

[7] F. Lali, G. Böttcher, P.-M. Schöneich, S. Haase, S. Hempel, and R. Lange, "Preparation and characterization of $\mathrm{Pd} / \mathrm{Al}_{2} \mathrm{O}_{3}$ catalysts on aluminum foam supports for multiphase hydrogenation reactions in rotating foam reactors," Chemical Engineering Research and Design, vol. 94, pp. 365-374, 2015.

[8] R. Lange, R. Gutsche, and J. Hanika, "Forced periodic operation of a trickle-bed reactor," Chemical Engineering Science, vol. 54, no. 13-14, pp. 2569-2573, 1999.

[9] R. Langsch, S. Haase, and R. Lange, "Hydrodynamics and mass transfer in a pellet string reactor for gas-liquid-solid reactions," Chemie-Ingenieur-Technik, vol. 85, no. 5, pp. 642-655, 2013.

[10] R. Langsch, J. Zalucky, S. Haase, and R. Lange, "Investigation of a packed bed in a mini channel with a low channel-to-particle diameter ratio: flow regimes and mass transfer in gas-liquid operation," Chemical Engineering and Processing, vol. 75, pp. 8$18,2014$.

[11] J.-N. Tourvieille, R. Philippe, and C. de Bellefon, "Milli-channel with metal foams under an applied gas-liquid periodic flow: external mass transfer performance and pressure drop," Chemical Engineering Journal, vol. 267, pp. 332-346, 2015.

[12] F. Turek and R. Lange, "Mass transfer in trickle-bed reactors at low Reynolds number," Chemical Engineering Science, vol. 36, no. 3, pp. 569-579, 1981.

[13] S. Haase and T. Bauer, "New method for simultaneous measurement of hydrodynamics and reaction rates in a mini-channel with Taylor flow," Chemical Engineering Journal, vol. 176-177, pp. 65-74, 2011.

[14] P. W. A. M. Wenmakers, J. Van Der Schaaf, B. F. M. Kuster, and J. C. Schouten, "Comparative modeling study on the performance of solid foam as a structured catalyst support in multiphase reactors," Industrial \& Engineering Chemistry Research, vol. 49, no. 11, pp. 5353-5366, 2010.

[15] C. Jakobitz, Investigation of reaction kinetics of the hydrogenation of $\alpha$-methylstyrene using surface modified and supported $P d / \gamma$ $\mathrm{Al}_{2} \mathrm{O}_{3}$ catalysts [Diploma Thesis], Technische Universität Dresden, Dresden, Germany, 2009.
[16] V. Meille, C. De Bellefon, and D. Schweich, "Kinetics of $\alpha$-methylstyrene hydrogenation on $\mathrm{Pd} / \mathrm{Al}_{2} \mathrm{O}_{3}$," Industrial \& Engineering Chemistry Research, vol. 41, no. 7, pp. 1711-1715, 2002.

[17] F. A. Pahner, Simulation of a hydrogeantion reaction on catalytically active foams [diploma thesis], TU Dresden, Dresden, Germany, 2014.

[18] VDI Atlas of Heat Trasfer, Springer, 2006.

[19] B. Chexal, J. Horowitz, G. McCarthy, M. Merilo, and J.-P. Sursock, Electric Power ResearchInstitute, 1999.

[20] P. Cognet, J. Berlan, G. Lacoste, P.-L. Fabre, and J.-M. Jud, "Application of metallic foams in an electrochemical pulsed flow reactor Part I: mass transfer performance," Journal of Applied Electrochemistry, vol. 25, no. 12, pp. 1105-1112, 1995.

[21] C. P. Stemmet, Gas-Liquid Solid Foam Reactors: Hydrodynamics and Mass Transfer, Technische Universiteit Eindhoven, 2008.

[22] K. Onda, H. Takeuchi, and Y. Koyama, "Effect of packing materials on the wetted surface area," Chemical Engineering, vol. 31, no. 2, pp. 126-134, 1967.

[23] K. Onda, H. Takeuchi, and Y. Okumoto, "Mass transfer coefficients between gas and liquid phases in packed columns," Journal of Chemical Engineering of Japan, vol. 1, no. 1, pp. 5662, 1968.

[24] C. P. Stemmet, F. Bartelds, J. van der Schaaf, B. F. M. Kuster, and J. C. Schouten, "Influence of liquid viscosity and surface tension on the gas-liquid mass transfer coefficient for solid foam packings in co-current two-phase flow," Chemical Engineering Research and Design, vol. 86, no. 10, pp. 1094-1106, 2008.

[25] P. M. Schöneich, Simulation of a hydrogeantion reaction on catalytically active foams [Diploma thesis], TU Dresden, 2011.

[26] H. S. Fogler, Elements of Chemical Reaction Engineering, Prentice-Hall, Englewood Cliffs, NJ, USA, 4th edition, 2005.

[27] G. F. Carey and B. A. Finlayson, "Orthogonal collocation on finite elements," Chemical Engineering Science, vol. 30, no. 5-6, pp. 587-596, 1975.

[28] B. A. Finlayson, "Orthogonal collocation in chemical reaction engineering," Catalysis Reviews, vol. 10, no. 1, pp. 69-138, 1974.

[29] A. Löwe, Chemische Reaktionstechnik: mit MATLAB und SIMULINK, Wiley-VCH, Weinheim, Germany, 2001.

[30] J. Villadsen, Solution of Differential Equation Models by Polynomial Approximation, Physical \& Chemical Engineering Science, Edited by M. L. Michelsen, Prentice Hall, Englewood Cliffs, NJ, USA, 1978 .

[31] J. V. Villadsen and W. E. Stewart, "Solution of boundary-value problems by orthogonal collocation," Chemical Engineering Science, vol. 22, no. 11, pp. 1483-1501, 1967.

[32] S. D. Conte and C. De Boor, Elementary Numerical Analysis/An Algorithmic Approach, McGraw-Hill, Auckland, New Zealand, 3rd edition, 1980.

[33] F. Lali, Catalytic Active Foams for Gas Liquid Solid Reaction, Technische Universität Dresden, Dresden, Germany, 2015.

[34] M. Schubert, "Performance enhancement of trickle bed reaktors," in Proceedings of the Annual Cardiovascular-Thoracic (CVT) Critical Care, Technische Universität Dresden, 2007. 


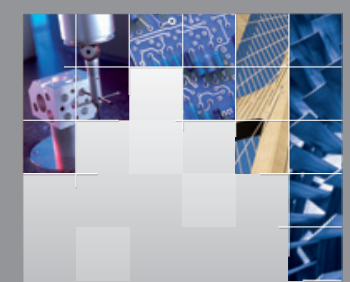

\section{Enfincering}
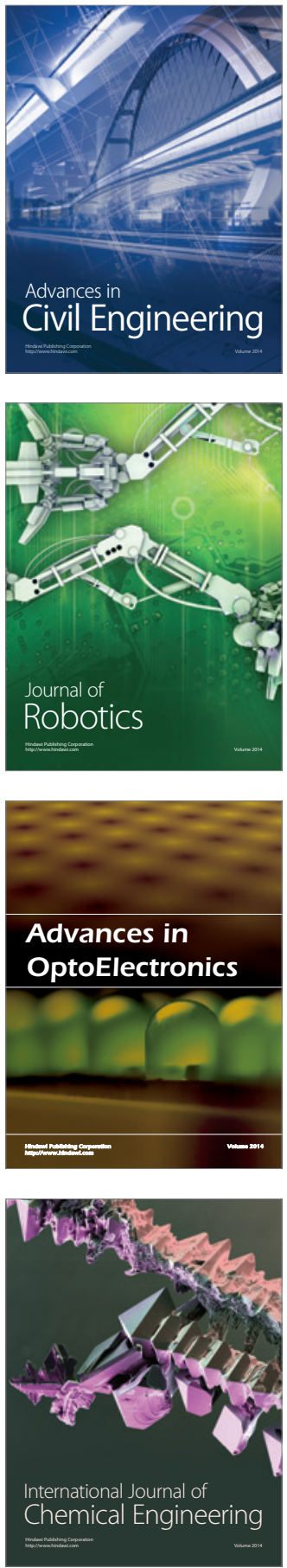

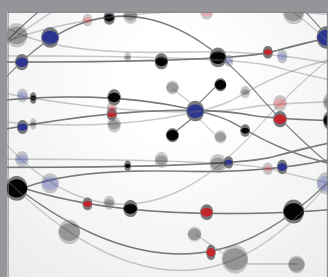

The Scientific World Journal

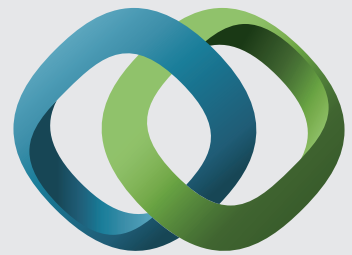

\section{Hindawi}

Submit your manuscripts at

http://www.hindawi.com
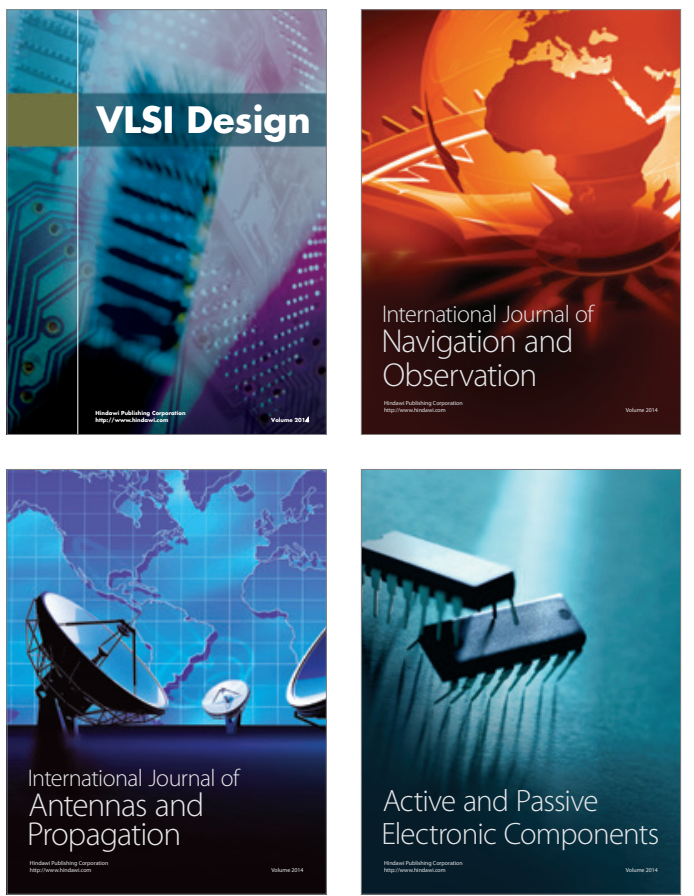
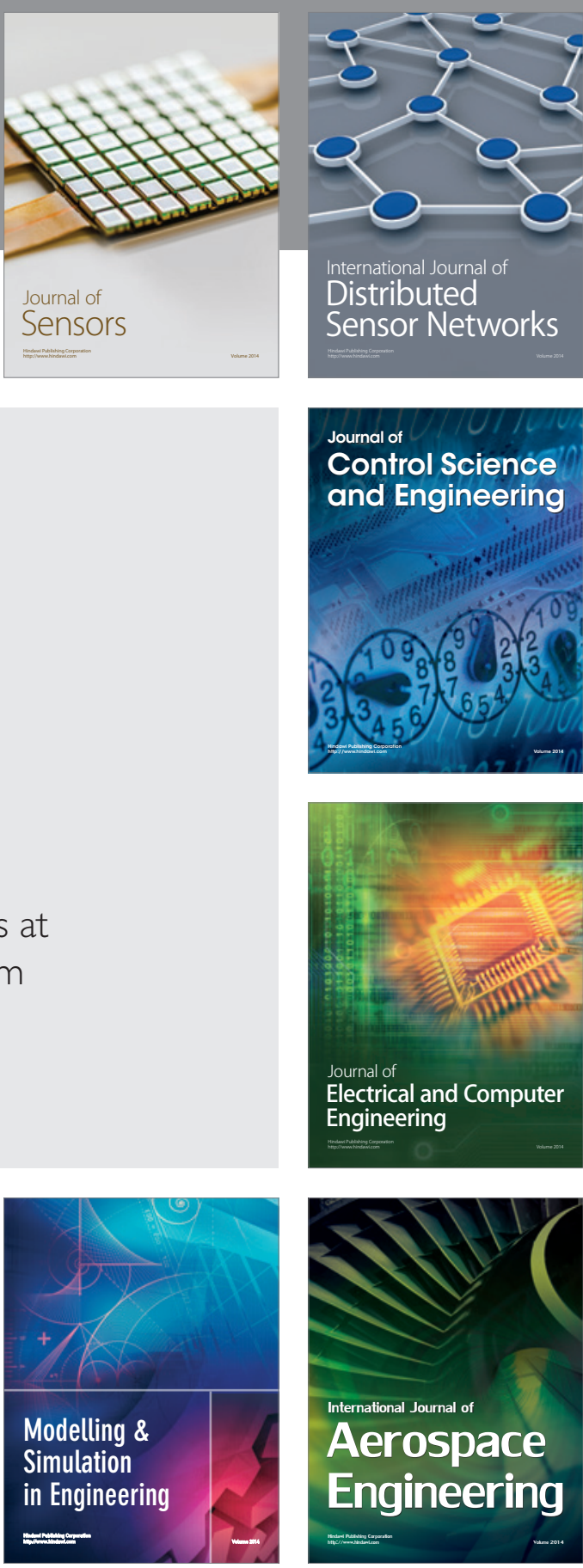

International Journal of

Distributed

Sensor Networks

Journal of

Control Science

and Engineering
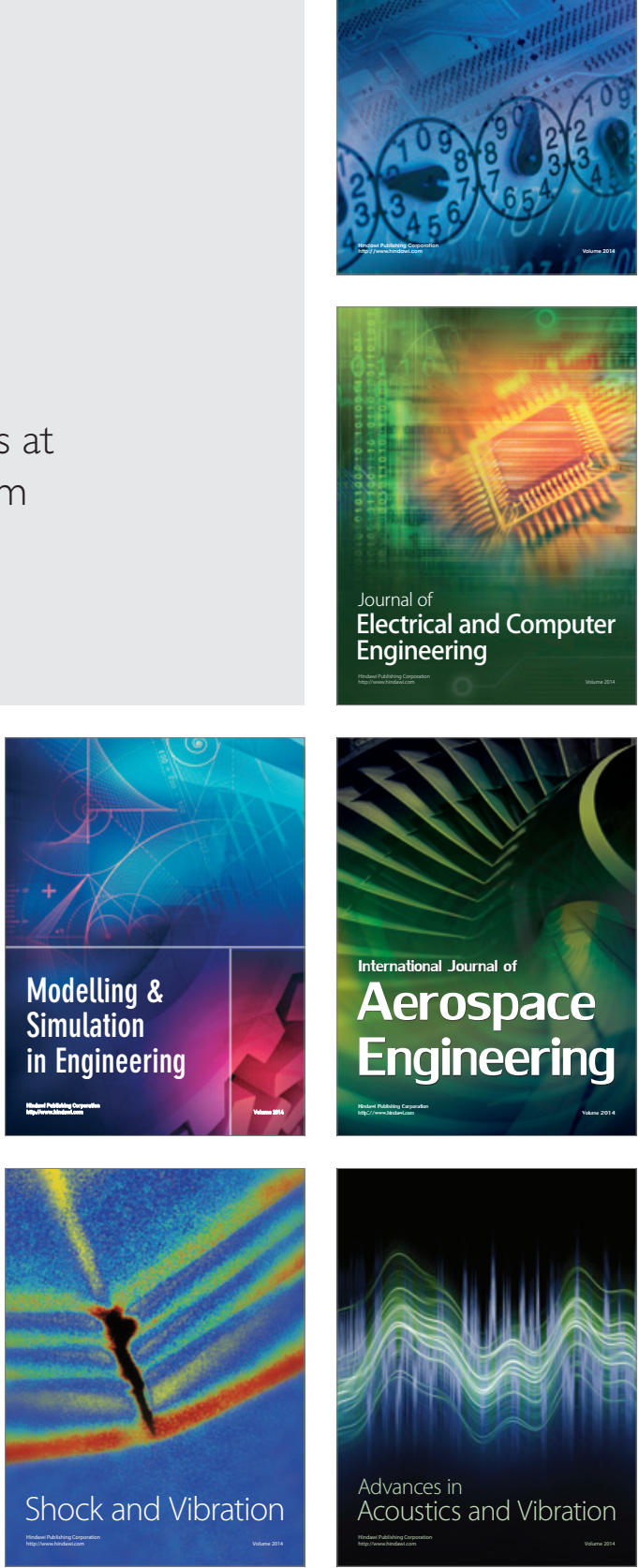